\title{
Blockchains, Real-time Accounting, and the Future of Credit Risk Modeling
}

\author{
Hans Byström*
}

\begin{abstract}
In this paper I discuss how blockchains potentially could affect the way credit risk is modeled, and how the improved trust and timing associated with blockchain-enabled real-time accounting could improve default prediction. To demonstrate the (quite substantial) effect the change would have on well-known credit risk measures, a simple case-study compares Z-scores and Merton distances to default computed using typical accounting data of today to the same risk measures computed under a hypothetical future blockchain regime.
\end{abstract}

\section{Introduction}

Most finance people have heard of Bitcoin, the virtual currency. Less, though, have probably heard of the technology behind Bitcoin, a technology labeled blockchain. While, to date, blockchain technology has been used primarily as the plumbing for Bitcoin, blockchains can also be used for the infrastructure of traditional financial products such as debt contracts and financial derivatives. ${ }^{1}$

In accounting, blockchains could potentially improve the quality of information reaching investors in two ways: by making the accounting information more trustworthy, and by making the information more timely. As for trust, if firms were to keep their financial records on blockchains, the opportunities for accounting-related manipulation and fraud etc. could drop dramatically. Inter-firm transactions would also become much more transparent. ${ }^{2}$ As for timing, since blockchain-based book keeping would make each and every transaction in a firm's ledger instantaneously available, real-time updating of accounting information would be possible. ${ }^{3}$ Moreover, this information would be made instantaneously available not only to insiders within the firm but to (chosen) outsiders like regulators., ${ }^{4,6}$

In this paper, my focus is on credit risk modeling and on how a possible future wide-spread use of blockchains could affect the way we model credit risk. It is well known that accounting information, such as balance sheet data and income statements, is imperfect. ${ }^{7}$ Accounting data suffers from problems such as ambiguous and non-uniform accounting practices, managers engaging in creative accounting or by reports lagging behind real events. Therefore, since most credit risk models rely on accounting data, the increased transparency, accuracy, and timeliness of financial statements brought about by firms keeping their books on blockchains, whether public or private, could significantly improve credit risk modeling. ${ }^{8}$

*H. Byström (hans.bystrom@nek.lu.se) is Professor of Economics at Lund University, Sweden. 
Of course, no one knows whether, and how quickly, the scenario outlined above will materialize. In the analysis in this paper, however, I generally assume that (i) publicly traded firms will upload their financial data on a public blockchain, (ii) this data will be uploaded very frequently, perhaps daily, and (iii) any accounting data required in credit risk modeling is indeed uploaded on this blockchain. In other words, the main point of this paper is not to discuss whether companies will or will not participate in a future blockchain scheme.

\section{Blockchains}

Bitcoin was first proposed in 2008 by an unknown author writing under the pseudonym Satoshi Nakamoto. Bitcoin is a virtual currency, i.e. a digital currency resembling cash but lacking central bank backing, offering a way of exchanging ownership on a peer-to-peer basis. Importantly, Bitcoin does not rely on a central clearing place, such as a bank. Instead, every historical Bitcoin transaction is stored in a globally distributed electronic ledger called the blockchain that keeps track of all Bitcoin transactions throughout history. ${ }^{9,10,11}$

The Bitcoin ledger is called a blockchain because blocks, or records, of new Bitcoin transactions are added to the chain of historical transactions, as they happen, by special Bitcoin users called miners. The miners verify that every Bitcoin transaction in the block is legitimate by solving a difficult cryptographic problem. ${ }^{12}$ This innovative technology, where new transactions are added to the (Bitcoin) blockchain and verified by the entire decentralized network, significantly reduces transactions costs. It is also fully transparent and it is secured by sophisticated cryptography (using mathematical algorithms called hash functions) and through the work of the miners.

\section{Blockchains and Real-Time Accounting}

A blockchain is basically a ledger that can never be altered and whose records can never be destroyed. As such, it could, among other things, be useful as a trustworthy and continuously updated ledger for a firm's accounting records. ${ }^{13}$ This is due to the fact that blockchain technology can be used not only to transfer digital currency between a buyer and a seller but also to transfer the ownership of any other asset between two firms in a cheap, efficient and trustworthy way. ${ }^{14}$

Financial statements are prepared at regular intervals and sum up what has happened in a firm's ledger throughout a certain period. An auditor then issues an opinion on the accuracy of the financial statements. Outsiders, such as investors and credit risk managers, have to trust both that the auditing is thorough and unbiased and that the firm has not given false information to the auditor. That is, the concept of trust is critical in both the preparation of the financial statement and in the auditing process. This is where the blockchain technology behind Bitcoin can play an integral role. ${ }^{13}$

If a firm were to voluntarily, perhaps due to market pressure, post all of its business transactions on a blockchain, with a permanent time stamp on each transaction, the firm's entire ledger would be instantaneously visible and anyone could aggregate the firm's transactions into income statements and balance sheets in real-time. ${ }^{2}$ That is, many of the things the auditor does in today's accounting world, a blockchain can possibly do much more efficiently and much more timely in tomorrow's. By construction, if a firm kept all its transactions and balances on a blockchain, then the blockchain itself could, to a large extent, replace the auditor in confirming the accuracy of the firm's accounting (avoiding potential moral hazard or agency problems). Since past transactions in the blockchain cannot be 
tampered with, the issue of mistrust is intelligently removed from the firm's financial statements.

In addition to the issue of trust, the automatic updating of the ledger in real time, where each and every transaction is (more or less) instantaneously included in the firm's blockchain, could potentially make a firm's accounting information as timely and dynamic as, for instance, its stock price. In other words, due to the natural parallels between blockchains and accounting, blockchain technology could improve the quality of accounting information reaching investors in two ways: by making the information more trustworthy and by making the information more timely.

\section{Blockchains and Credit Risk Modeling}

Two of the most well-known credit risk models are the Altman Z-score and the Merton (1974) model. ${ }^{15,16}$ The Z-score formula for predicting bankruptcy was developed by Edward Altman in the late 1960s and uses various corporate income and balance sheet variables (i.e. accounting information), plus stock prices, to predict whether a firm will go bankrupt or not.

The Z-score is a linear combination of five financial ratios, weighted by coefficients. The coefficients were estimated by Altman using discriminant analysis on a matched set of bankrupt and non-bankrupt firms. The Z-score is calculated as

$$
Z=1.2 X_{1}+1.4 X_{2}+3.3 X_{3}+0.6 X_{4}+0.99 X_{5}
$$

where

$$
\begin{aligned}
& X_{1}=\text { working capital/total assets, } \\
& X_{2}=\text { retained earnings/total assets, } \\
& X_{3}=\text { earnings before interest and taxes/total assets, } \\
& X_{4}=\text { market value of equity/book value of total liabilities, } \\
& X_{5}=\text { sales/total assets, }
\end{aligned}
$$

and the larger the Z-score the smaller the probability that the firm will default on its debt.

The Merton model, in turn, also relies on accounting information and stock prices as inputs, but views a firm's equity and debt as contingent claims issued against the firm's underlying assets. ${ }^{17}$ In the Merton model

$$
V_{E}=V_{A} N\left(d_{1}\right)-e^{-r(T-t)} D N\left(d_{2}\right)
$$

where $N()$ is the cumulative normal distribution, and

$V_{E}$ is the firm's market value of equity, $\mathrm{V}_{\mathrm{A}}$ is the firm's market value of assets, $\mathrm{D}$ is the total amount of firm liabilities, $\mathrm{T}-\mathrm{t}$ is the time to maturity of the firm's liabilities, $\mathrm{r}_{\mathrm{f}}$ is the risk-free interest rate, 


$$
\begin{gathered}
d_{1}=\frac{\ln \left(\frac{V_{A}}{D}\right)+\left(r+\frac{\sigma_{A}{ }^{2}}{2}\right)(T-t)}{\sigma_{A} \sqrt{T-t}}, \\
d_{2}=d_{1}-\sigma_{A} \sqrt{T-t}
\end{gathered}
$$

Moreover, the equity volatility $\sigma_{\mathrm{E}}$ and the asset volatility $\sigma_{\mathrm{A}}$ are related through the equation

$$
\sigma_{E}=\frac{V_{A} N\left(d_{1}\right) \sigma_{A}}{V_{E}}
$$

and one can solve the nonlinear system of equations (1) and (2) for $\mathrm{V}_{\mathrm{A}}$ and $\sigma_{\mathrm{A}}$. The distance to default is then defined as

$$
D D=\frac{\ln \left(\frac{V_{A}}{D}\right)+\left(r-\frac{\sigma_{A}^{2}}{2}\right)(T-t)}{\sigma_{A} \sqrt{T-t}}
$$

and the larger the value of DD the smaller the probability that the firm will default on its debt.

4.1 A Case Study - To demonstrate the effect of going from a quarterly updating of accounting information to a near instantaneous updating I look at the two credit risk models described above applied to the two well-known US-based companies Apple and Groupon. Since these firms' accounting information is sampled quarterly, i.e. the risk measures cannot be updated more frequently than once every three months, I have to simulate hypothetical (blockchainenabled) day-to-day movements of the Z-score and the DD measure. ${ }^{18}$ These daily movements are generated by sampling normally-distributed random numbers with means and standard deviations estimated from the actual history of quarterly sampled Z-scores and debt levels (for the Merton DD measures), respectively, using the square-root rule assuming that the daily movements are independent. In this way I get reasonably realistic realizations of potential future blockchain-induced real-time Z-scores and DDs.

Figure 1 shows the Z-score and the Merton distance to default (DD) measure for the two firms, with daily and quarterly accounting data, respectively. ${ }^{19,20}$ Since the volatility of the hypothetical daily changes in risk is chosen based on the volatility of the firms' actual quarterly changes in risk and debt, the (fairly substantial) fluctuations in the two figures give a reasonably realistic demonstration of how, and of how much, the estimated risk measures would change as a result of the introduction of blockchains in firms' book keeping. The intra- 
quarterly fluctuations are not insignificant, indicating improved credit risk modeling when going from quarterly to daily updating of accounting information. ${ }^{21}$
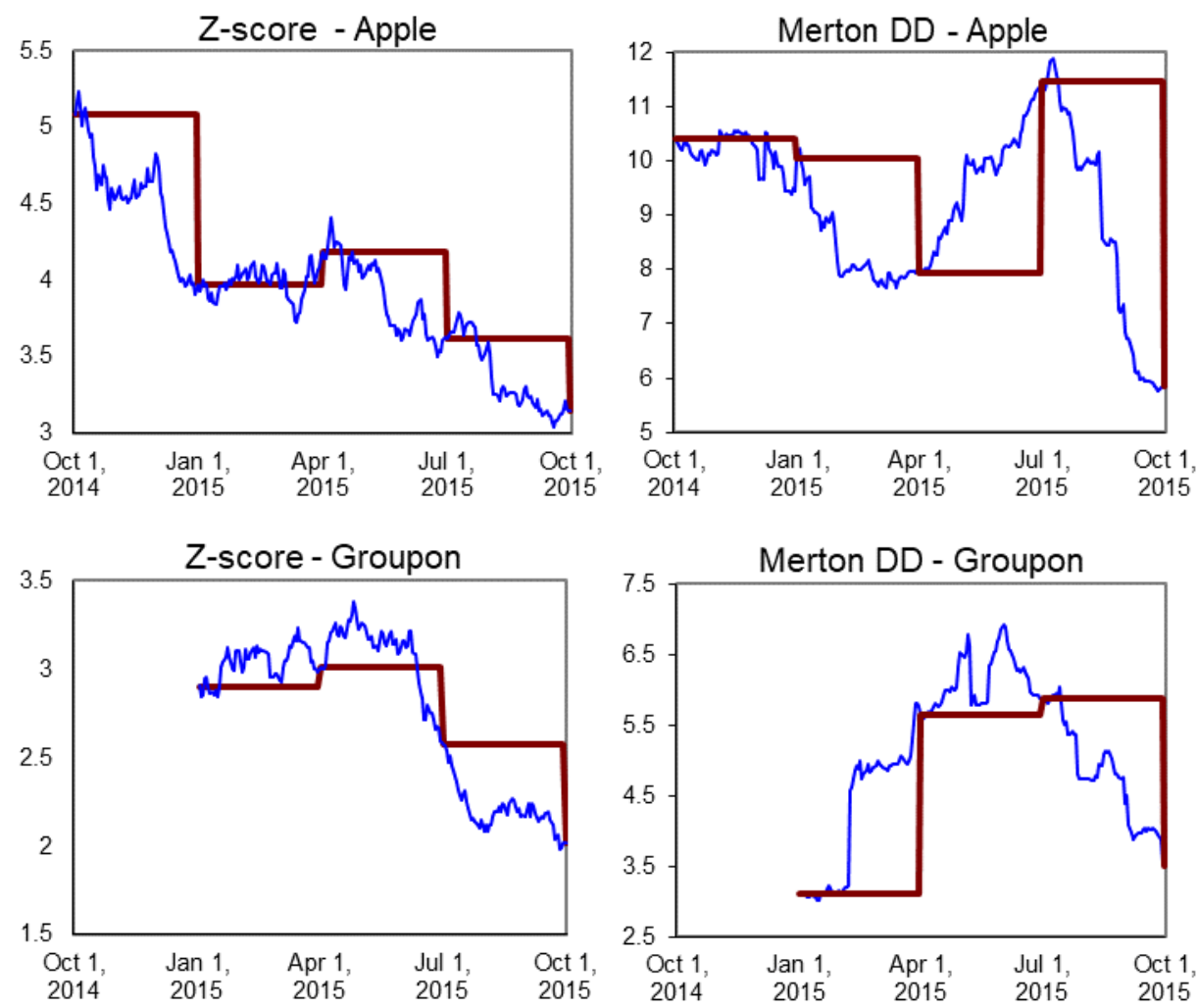

Fig. 1. Z-score and Merton DD (Distance to Default) for Apple and Groupon with daily and quarterly accounting data, Oct 2014 - Oct 2015.

As mentioned, the dynamics of the Z-scores and distance to defaults (DDs) in Figure 1 suggests that credit risk measurement could be significantly improved if blockchain-based real-time accounting was available. For example, the average change in Z-score and DD from one quarter to the next is $13 \%$ and $36 \%$, respectively (for these two particular firms and for this time-period). In other words, even if we, somewhat simplistically, assumed a linear change in actual Z-scores and DDs from one quarter to the next the credit risk modeling error compared to the actual credit risk levels would be on average $6.5 \%$ and $18 \%$, respectively, on any given day in between the quarterly updates. Moreover, if the intra-quarterly changes in risk are modeled, somewhat more realistically, using the stochastic processes in this paper the modeling error could be much larger than these numbers, as Figure 1 shows. One extreme example is the third-quarter distance to default for Groupon where the modeling error is significantly larger. Moreover, in the case of the Merton model, and possibly also for the Zscores, the magnitude of the error is even larger when one looks at default probabilities (PDs) rather than distance to defaults. ${ }^{22}$ As for the timing of the risk assessment, regardless of credit risk modeling method, the blockchain-based risk measure reaches next quarter's credit risk level early 75\% (Apple) and 67\% (Groupon) of the time (for this particular generation of stochastic numbers). On average, with real-time accounting the next quarter's risk levels are 
reached after around two months (i.e. one month early) and in some cases the level is reached already after a couple of weeks.

Figure 1 shows that the risk dynamics are similar for the Z-score and the Merton DD measure but, considering the more typical dynamic (daily) implementation of the Merton model, the Z-score is probably the measure that, in practice, would be most affected by the introduction of real-time accounting. It is even possible that the (rather dated) Z-score could experience a renaissance as a result of the introduction of blockchains. In fact, with the drastic changes to the accounting and auditing practice described above the current $Z$-score would probably be replaced with a new score containing other financial ratios and/or coefficients.

It is also possible that the entire area of bankruptcy prediction could change, with a focus on new instruments (smart contracts in blockchain jargon) or financial ratios directly tailored to the likelihood of default. With not only insiders having access to all of a firm's transactions, the process of bankruptcy might also change fundamentally with managers, creditors, investors, and regulators playing by entirely new rules. Issues such as reflexivity could affect a firm's path towards bankruptcy to a larger extent than today.

Finally, it should be stressed that even if the process of firms posting all of their business transactions on a blockchain was to be more limited than that hypothesized above it is still likely that credit risk models would be affected in one way or the other. For instance, even if not all accounting information would be instantaneously available on the blockchain, perhaps some will.

\section{Conclusion}

Above, I have discussed how the blockchain technology behind the bitcoin could improve credit risk modeling through improved trust and better timing of accounting data releases. If the suggested changes were to materialize over the coming years the impact on the way we model credit risk could be substantial, and with a simple case-study I find that blockchains would have a material effect also on credit risk measures widely used today.

\section{Acknowledgements}

Financial assistance from Marianne and Marcus Wallenberg Foundation and Handelsbankens Forskningsstiftelser is gratefully acknowledged. Parts of the paper were written when the author visited $E S A D E$ in Barcelona and the author would like to thank five anonymous referees.

\section{Notes and References}

${ }^{1}$ One recent example is the February 2016 decision by the Australian Stock Exchange to become the world's first market to settle equities trades using blockchains. See: Stafford, P. "Backers of Blockchain Technology Urged to Consider Protecting Users From Fraud." Financial Times (25 January 2016). https: //www. ft.com/content/fba22346-c370-11e5-b3b1$7 \mathrm{~b} 2481276 \mathrm{e} 45$.

2 Yermack, D. "Corporate Governance and Blockchains." Working paper, NYU (2015). http://www. nber.org/papers/w21802.pdf. 
${ }^{3}$ While real-time accounting traditionally often means that the books of a firm are updated monthly or quarterly, in the future world of blockchains envisioned in this paper the term really means near-instant (daily) updating of accounting information. Current practice of borrowers providing updated accounts in between regular reports, on a case-by-case basis and provided only to potential lenders, cannot really be labelled real-time accounting as defined in this paper, either.

${ }^{4}$ Throughout this paper, when referring to blockchains, I typically mean public blockchains, not private ones. Of course, while many firms might not voluntarily reveal all their checks and balances on a public ledger, one could think of a situation where the most important numbers (such as sales, leverage etc.) are made public while the rest are kept private, or are distributed to a few selected participants through a private blockchain. In other words, even if a future blockchain environment will be populated by numerous private (permissioned) networks hidden from the public eye, certain vetted entities, such as regulators and credit rating agencies, could be provided with readily updated balance sheet information through the distributed ledger. The full, or partial, release of balance sheet information could be driven by regulation or, possibly, by market forces (if some company releases information on a public ledger, perhaps other firms feel forced to follow suit). An alternative possible avenue is the use of so-called sidechains, where companies use private blockchains that are periodically (partly) connected to the main (public) blockchain.

${ }^{5}$ Privacy issues are important to most firms and forces that want to minimize the number of actors getting full access to one's financial statements in real-time will probably always exist. For example, one could think of situations where only shareholders who hold a certain minimum number of shares get access to the ledger (if it is not fully public, that is).

${ }^{6}$ As for the sheer scale of a ledger necessary to harbor all this data, some kind of change to the general blockchain design will undoubtedly be necessary; perhaps a block size adjustment, like the "hard fork" leading to the launch of Bitcoin Cash. A detailed discussion of technical issues like this and the privacy issues in the previous footnote is deliberately left out of this paper.

${ }^{7}$ Duffie, D., Lando. D. "Term Structures of Credit Spreads with Incomplete Accounting Information." Econometrica 69.3 633-664 (2001) https : / doi .org/10.1111/14680262.00208 .

${ }^{8}$ Of course, new kinds of risk linked to the creation of huge blockchains of company accounting information, perhaps operational risk in association with the administration of the blockchains, should not be ignored. No doubt, there will be errors and unexpected problems also in a fully public ledger. While acknowledged, this kind of (potential) risk will not be further discussed in this paper, though.

${ }^{9}$ Nakamoto, S. "Bitcoin: A Peer-to-Peer Electronic Cash System.” (2008)

https://bitcoin.org/bitcoin.pdf.

${ }^{10}$ Antonopoulos, A. M. Mastering Bitcoin, O’Reilly Media Inc. (2014).

${ }^{11}$ Swan, M. Blockchain Blueprint for a New Economy. O’Reilly Media, Inc. (2015).

${ }^{12}$ The fastest miner is rewarded with a number of bitcoins for this service. A new block is won approximately every ten minutes and since the losing miners get nothing, bitcoin mining is sometimes called "competitive bookkeeping." See: Harvey, C. R. "Cryptofinance." Working Paper, Duke University (2016) https://papers.ssrn.com/sol3/Papers.cfm?abstract - id $=2438299$. 
${ }^{13}$ Lazanis, R. "How Technology Behind Bitcoin Could Transform Accounting as We Know It." Techvibes (2015) https: / techvibes . com/2015/01/22/how-technology-behindbitcoin-could-transform-accounting-as-we-know-it-2015-01-22.

${ }^{14}$ There is already some experimenting going on along this avenue. NASDAQ, for instance, is experimenting with "colored coins" as a way to use blockchains to record equity transactions. See: Hern, A. "Nasdaq Bets on Bitcoin's Blockchain as the Future of Finance." The Guardian (13 May 2015) https://www. theguardian.com/technology/2015/may/13/nasdaq-bitcoinblockchain.

${ }^{15}$ Altman, E. "Financial Ratios, Discriminant Analysis and the Prediction of Corporate Bankruptcy." Journal of Finance 23.4 589-609 (1968) https : / doi . org/10 .1111/j . 1540 6261.1968. tb00843.x.

${ }^{16}$ Merton, R. "On the Pricing of Corporate Debt: The Risk Structure of Interest Rates." Journal of Finance $29.2 \quad 449-470$ (1974) https://doi.org/10.1111/j.1540-6261.1974 .tb03058.x.

${ }^{17}$ By backing out asset values and volatilities from stock prices and balance sheet information the model produces estimates of a firm's default probability. The Merton model uses the Black and Scholes framework to solve for the asset value and volatility implied by the stock price and volatility. The asset value and the asset volatility can then be combined into a risk measure called distance to default (DD) that is inversely related to the default probability of the firm. See: Black, F., Scholes, M. "The Pricing of Options and Corporate Liabilities." Journal of Political Economy 81 637-659 (1973) https://doi.org/10.1086/260062.

18 The necessary accounting variables are total assets, total liabilities, working capital, retained earnings, EBITDA and sales for the Z-score and total liabilities for the Merton model. The data is downloaded from Yahoo Finance and covers the time-period October 2014 to October 2015 for Apple and January 2015 to October 2015 for Groupon.

${ }^{19}$ To isolate the effect of the real-time accounting on the dynamics of the two credit risk measures I sample the stock price on a quarterly basis all through the analysis. While this might be typical in applications of the Z-score, it is more common to update the stock price on a daily basis when using the Merton model.

${ }^{20}$ In the Merton model, the stock return volatility is computed using daily data from the past quarter, and the risk-free interest rate is set to $10 \mathrm{bp}$.

${ }^{21}$ By improvement I mean that the measures of risk are more updated, or timely, since more updated input information is used. With (only) quarterly updated accounting information, for example, any measure of risk based on accounting information is typically several weeks or months old.

${ }^{22}$ The reason for this is the highly non-linear relationship between PDs and DDs, which in the standard Merton model is given by the mathematical properties of the normal distribution and in models like Moody's KMV by in-house databases.

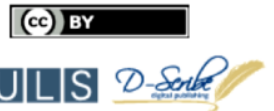

ledgerjournal.org
Articles in this journal are licensed under a Creative Commons Attribution 4.0 License.

Ledger is published by the University Library System of the University of Pittsburgh as part of its D-Scribe Digital Publishing Program and is cosponsored by the University of Pittsburgh Press. 